\title{
ADOÇÃO DE CRIANÇAS POR CASAIS HOMOAFETIVOS: UM ESTUDO COMPARATIVO ENTRE UNIVERSITÁRIOS DE DIREITO E DE PSICOLOGIA
}

\author{
Ludgleydson Fernandes de Araújo \\ Universidade Federal do Piauí, Parnaíba, Brasil \\ Josevânia da Silva Cruz de Oliveira \\ Valdiléia Carvalho de Sousa \\ Universidade Federal da Paraíba, João Pessoa, Brasil \\ Alessandra Ramos Castanha \\ Universidade de São Paulo, São Paulo, Brasil
}

\begin{abstract}
RESUMO: Esta pesquisa objetivou analisar e comparar as Representações Sociais (RS) de estudantes em fase final do curso de psicologia e de direito acerca da adoção de crianças por casais homossexuais. Para tanto a amostra foi nãoprobabilística e intencional constituída de 104 universitários, de ambos os sexos (56\% feminino e 44\% masculino), sendo 51 concluintes do curso de Direito e 53 concluintes do curso de Psicologia. Utilizaram-se questionários com perguntas fechadas. Posteriormente foi categorizada pela análise de conteúdo temática de Bardin (1977/2000). Perceberam-se posicionamentos contrários dos universitários acerca da adoção de crianças por casais homossexuais. No que diz respeito às consequiências para a criança emergiram conteúdos tais como: influência na orientação sexual, preconceito e ausência de referencial materno/paterno. Os universitários de Psicologia mencionaram que tal fato poderia desenvolver distúrbios psicológicos, ao passo que os universitários de Direito ancoraram suas RS nos problemas morais. Evidenciou-se a necessidade do fomento de mecanismos psicossociais e jurídicos que contribuam na elucidação desta temática complexa e dinâmica na sociedade contemporânea.
\end{abstract}

PALAVRAS-CHAVE: Adoção; casais homoafetivos; representações sociais.

\section{CHILDREN ADOPTION BY HOMOSEXUAL COUPLES: A COMPARATIVE STUDY BETWEEN LAW AND PSYCHOLOGY STUDENTS}

\begin{abstract}
The objective of this research was to analyze and to compare the Social Representations of last year's undergraduate law and psychology students regarding the adoption of children by homosexual couples. For this purpose, the sample was non-probabilistic and intentional and it was composed of 104 students of both genders (56\% female and 44\% male); 51 students were graduating in Law, and 53 were graduating in Psychology. Closed questioned questionnaires were used. The data was categorized by Bardin's (1977/2000) thematic content analysis. Contrary attitudes were perceived from the students regarding the adoption of children adoption by homosexual couples. Concerning the consequences to the child, contents such as influence on sexual orientation, prejudice and absence of maternal/paternal reference, were raised. The Psychology students mentioned that the adoption could cause psychological disturbances, while the Law students based their Social Representations on moral issues. The necessity for psychosocial and jurist mechanisms that can contribute in elucidating this complex and dynamic subject in contemporary society was evidenced.
\end{abstract}

KEYWORDS: Adoption; homosexual couples; social representations.

As mudanças ocorridas na configuração familiar ao longo da história vêm ampliando a concepção do termo família. Tais arranjos não devem ser entendidos como decorrentes de uma crise na instituição família, mas como reflexo de mudanças na sociedade. No que se refere à questão da adoção de crianças por pares homoafetivos, há que se considerar os vários fatores intrínsecos, entre os quais se destaca o preconceito, que em muitos casos fundamenta atitudes violentas contra homossexuais.

Giddens (1993) afirma que essas transformações contribuíram para o surgimento de novas formas de relacio- namentos, conjugalidade e parentalidade. Assim, há uma reinvenção dos limites e características que compreendem a concepção clássica de família, baseada num modelo de união entre um homem e uma mulher para fins de procriação e transmissão dos bens (Mello, 2005).

Na contemporaneidade, o casamento não é garantia para uma vida sexual plena, e o objetivo das uniões conjugais já não possui mais como foco a geração de filhos, mas busca-se, além do prazer sexual, uma relação que "presume igualdade na doação e no recebimento emocionais" (Giddens, 1993, p. 173). 
O novo conceito de família trazido pela Constituição Brasileira de 1988 foi uma tentativa de acompanhar as mudanças ocorridas na vida íntima da sociedade (Costa, 2006). Nessa nova definição, a família compreende a união relativamente estável entre homem e mulher, e comunidade constituída por "qualquer um dos pais e seus descendentes", tendo o homem e a mulher os mesmos direitos e deveres conjugais (Torres \& Falcão, 2005). No entanto, hoje verifica-se um contingente significativo de uniões conjugais formadas por pares homoafetivos, os quais não estão compreendidos na nova definição de família da Constituição Brasileira. Assim, na realidade brasileira, a união civil de pessoas do mesmo sexo bem como o direito à adoção de crianças ainda não são legitimados juridicamente.

Essa diversidade de configuração familiar tem suscitado uma variedade de conceitos sobre família na área da Psicologia, da Sociologia e do Direito (Torres \& Falcão, 2005). Nesse sentido, em 1995, a ex-deputada Marta Suplicy apresentou à Câmera dos Deputados o Projeto de Lei de $n^{\circ} 1.151 / 95$, que objetivava assegurar aos pares homoafetivos o direito a propriedade, a sucessão, a usufruto, a benefícios previdenciários, entre outros (Lopes, 2006). Entretanto, Torres e Falcão (2005) ressaltam que esse projeto defende a legalização da Parceria Registrada e não o "status" equivalente ao casamento.

Os membros das relações conjugais homoafetivos se autodefinem como famílias e exigem não apenas o direito à cidadania a nível individual, mas também o direito à constituição de famílias enquanto sujeitos sociais e, portanto, responsáveis pela educação e socialização de filhos, quer biológicos, quer adotivos (Mello, 2005).

No Estatuto da Criança e do Adolescente ([ECA], 1990), não há artigo que proíba a adoção de crianças por homossexuais; todavia, uma vez que a união destes não é considerada família, a adoção só seria possível a nível individual, ou seja, por um dos pares. Verifica-se, dessa forma, que a adoção de crianças por pares homossexuais está relacionada ao reconhecimento desses casais enquanto família (Costa, 2006).

De outro modo, alheios às discussões na sociedade acerca desse tema, verifica-se a existência de um contingente de crianças e adolescentes à espera da sua inserção em um contexto familiar. Weber (2007) salienta que crianças e adolescentes institucionalizados são afetadas psicologicamente devido a uma restrita inserção social e a uma dificuldade de se estabelecer e manter vínculos afetivos dentro dessas instituições. Ademais, segundo a mesma autora, verifica-se a formação de uma auto-imagem negativa, o que por sua vez interfere no desenvolvimento humano dessas pessoas, bem como nas relações interpessoais que estabelecem.

Crianças e adolescentes têm o direito à convivência familiar e comunitária, ou seja, enquanto atores sociais possuem o direito ao estabelecimento de vínculos afetivos e sociais. Os critérios para a seleção do que venha a ser uma família ideal e apta para adotar uma criança se tornam menos prioritários quando se considera a situação de abandono de muitas crianças (Weber, 2007). Assim, se faz necessário ampliar e superar os debates concernentes à adoção, família e prática sexual.

O ECA (1990) norteia que, no processo de adoção, deve-se considerar como prioridade as reais vantagens para o adotando. Destarte, a adoção, quer por homossexuais, quer por heterossexuais, apresenta-se como uma via real de inclusão e respeito aos direitos da criança e/ou adolescente (Alves, Oliveira, Baroni, Franco \& Zacarias, 2007).

As discussões acerca da negação do direito aos homossexuais de constituir família, na qualidade de cidadãos, perpassam as esferas dos direitos humanos fundamentais, uma vez que lhes são negados esse direito, ainda que os pares possuam vínculos afetivos-sexuais estáveis (Mello, 2005). Ademais, para esse autor, tais posturas dizem respeito a atos de discriminação e exclusão social.

Machado (2004) disserta que os estudos da psicologia sobre as "visões sociais de discriminação" têm como foco principal o preconceito e os estereótipos. Tais construtos estariam a nível de consciência individual e coletiva. Assim, Jones (1972) definirá preconceito como um "préjulgamento" negativo acerca de um grupo social, quer seja uma raça, religião, entre outros. Entretanto, os preconceitos não são apenas crenças distorcidas e um posicionamento afetivo contra determinado grupo social (Machado, 2004); mas envolve comportamentos em situações concretas de discriminação.

Numa perspectiva psicossocial, o preconceito perpassa questões políticas e ideológicas. O mesmo desenvolve-se nos grupos majoritários (entendido aqui como possuidor do poder político) e expressam-se por meio de atitudes de caráter discriminatório em relação aos membros dos grupos minoritários (Camino \& Pereira, 2000). Desse modo, ao se analisar as formas de preconceito na contemporaneidade, faz-se necessário também verificar a natureza das relações inter-grupais (e não apenas inter-individual) dos sujeitos sociais, as suas formas de comunicação e os discursos existentes.

Os discursos elaborados acerca da homossexualidade no percurso da história passaram por várias configurações: ora como uma prática cultural, na Grécia e Roma (Ivo, Pelizaro \& Zaleski, 2002; Lacerda, 2001; Lacerda, Pereira \& Camino, 2002), ainda que repudiada nos casos que ofereciam algum risco à ordem social; ora como pecado, na Idade Média; ora como patologia, definida pela medicina no século XIX (Mello, 2005; Tylor, 1999). Esses discursos eram mais que explicações ou opiniões individuais, refletiam crenças socialmente aceitas - "verdades" que se apoiavam em "teorias científicas" predominantes 
em determinado período histórico (Machado, 2004). Na contemporaneidade, as explicações para a homossexualidade vêm sendo substituídas (Machado, 2004) e verifica-se a existência de novos discursos e formas de preconceitos contra homossexuais.

O estudo desenvolvido por Lacerda, Pereira e Camino (2002) com 220 estudantes de três cursos universitários (Psicologia, Engenharia e Medicina) teve por objetivo verificar as formas como os estudantes expressavam o preconceito contra homossexuais. Nesse estudo, foram analisadas a rejeição à intimidade e a expressão de emoções positivas e negativas. Os resultados apontaram para a existência de três categorias de preconceito: flagrantes, sutis e não preconceituosos. Os preconceituosos fragrantes apresentaram altas pontuações na escala de rejeição à intimidade e expressaram muitas emoções negativas; os sutis apresentaram pouca rejeição à intimidade e poucas emoções negativas, mas negaram a expressão de emoções positivas, não contrariando as normas anti-preconceituosas de forma explícita; por fim, os não preconceituosos apresentaram baixa rejeição à intimidade, pouca emoção negativa e expressaram muitas emoções positivas. Do total de estudantes, três quartos foram classificados como preconceituosos; destes, metade flagrante e metade sutil. Em relação aos estudantes não preconceituosos, 36\% apresentaram um perfil semelhante aos do sutil.

Denota-se que, acerca das explicações da homossexualidade, os estudantes de Psicologia se posicionam positivamente em relação às explicações de cunho psicológico e psicossocial; já os estudantes de Medicina aderem às explicações biológicas e, por último, os estudantes de Engenharia posicionam-se positivamente em relação às explicações ético-morais e religiosas. Esses achados demonstram que a forma de posicionamento das pessoas em relação a algumas questões dos direitos humanos é mediada pelas teorias científicas ou de senso comum compartilhadas por elas (Lacerda, 2001).

A noção de representação social no campo de Psicologia Social possibilitou o estudo sobre essas formas de conhecimento que traduzem o pensamento do senso comum da sociedade contemporânea (Moscovici, 2003). Assim sendo, as representações sociais compreendem uma construção de significados sobre o meio social, orientando a conduta dos sujeitos sociais e, por outro lado, modelando o meio social em que o comportamento se reproduz nas relações interpessoais da vida cotidiana (Lacerda, Pereira \& Camino, 2002).

Assim, esse estudo teve por objetivo apreender, identificar, analisar e comparar as Representações Sociais de estudantes em fase final do curso de Psicologia e de Direito acerca da adoção de crianças por casais homossexuais.

As Representações Sociais são constituídas por processário saber/identificar quais as representações que os futuros profissionais de Psicologia e Direito enquanto atores sociais possuem acerca da problemática em questão, uma vez que a mesma evoca aspectos de cunho psicológico e sócio-jurídico.

Ao se referir ao tipo de representação que interessa ao estudo das RS, Moscovici (2003) afirma:

As representações sociais que me interessam não são nem as das sociedades primitivas, nem as suas sobreviventes, no subsolo de nossa cultura dos tempos pré-históricos. Elas são as de nossa sociedade atual, de nosso solo político, científico, humano, que nem sempre têm tempo suficiente para se sedimentar completamente, para se tornarem tradições imutáveis (p. 48).

Para Jodelet (2001), representar é tornar consciente, construir cognitiva e simbolicamente algo (pessoa, objeto, idéia, acontecimento etc.) que está ausente ou distante, tornando-o presente através de imagens (signos). Esta é uma peculiaridade fundamental da representação que lhe permite fusionar percepção e conceito.

Vala (2000) define alguns critérios básicos para as representações serem sociais: o critério social, o genético e o funcional. Refere-se o primeiro ao fato de serem elas um conhecimento partilhado por um grupo de pessoas (critério quantitativo). $\mathrm{O}$ segundo diz respeito às representações serem produzidas coletivamente. Finalmente, o terceiro critério enfatiza o caráter de praticidade ou da função de representação, que é a de propiciar a comunicação e a ação.

Diante do exposto, o presente trabalho objetiva analisar e comparar como os universitários concluintes dos cursos de Direito e Psicologia representam a adoção de crianças por casais homoafetivos. Recorreu-se à Teoria das Representações Sociais, considerando que, por estas consistirem num processo dinâmico, situado na articulação do social e do psicológico, permitem conhecer a formação do pensamento social.

\section{Método}

\section{Campo de investigação}

O presente estudo foi realizado numa instituição pública de ensino superior no município de João Pessoa-PB. A escolha do locus dessa investigação deu-se devido a sua relevância na formação profissional/acadêmica no contexto paraibano.

\section{Participantes}

Participaram da pesquisa 104 universitários, de ambos os sexos ( $56 \%$ feminino e $44 \%$ masculino), sendo 51 concluintes do curso de Direito e 53 concluintes do curso de Psicologia escolhidos de forma não-probabilística e intencional, com média de idade de 27 anos $(D P=3,36)$. Tendo-se em vista a randomização da amostra, optou-se 
por não se considerar as diferenças de gênero e idade na estruturação dos grupos. É válido mencionar que era necessário os participantes estarem no último período das respectivas áreas do conhecimento, uma vez que - se infere - estariam mais identificados com sua futura profissão.

\section{Instrumento}

$\mathrm{Na}$ coleta de dados, foram utilizados questionários, divididos em duas partes: a primeira constituída de itens referentes à identificação sociodemográfica dos participantes, definindo o seu perfil; e a segunda, composta de uma pergunta: Qual a sua opinião sobre a adoção de crianças por casais homossexuais? O roteiro do questionário foi elaborado previamente, tendo como pressupostos os objetivos da pesquisa e o estado atual da arte. Realizou-se um estudo piloto com o intuito de verificar a boa adequação do instrumento, e verificou-se a validade semântica do instrumento; em seguida, efetuou-se o estudo definitivo.

\section{Procedimentos de coleta de dados}

Inicialmente, foi mantido contato com as coordenações dos referidos cursos, com a finalidade de explicar os objetivos da pesquisa e a necessidade da participação dos estudantes. As entrevistas foram realizadas de forma individual na própria Universidade, por dois pesquisadores previamente treinados e qualificados; o tempo de aplicação foi, em média, de 25 minutos para cada participante. Informa-se, ainda, que não houve recusa por parte de nenhum universitário.

\section{Análise dos dados}

No que se refere à análise dos dados desta pesquisa, utilizou-se a análise de conteúdo temática de Bardin (1977/ 2000), cujo objetivo é compreender o sentido das comunicações e suas significações explícitas e/ou ocultas. Seu procedimento visa ainda obter a sistematização e descrição dos conteúdos das mensagens, os quais permitem a inferência de conhecimentos relativos às condições de produção/recepção (variáveis inferidas). Foram analisados quantitativamente por meio da análise das freqüências e percentuais. A análise das unidades temáticas por meio dessa técnica pressupõe o desenvolvimento das seguintes etapas operacionais: constituição do corpus; leitura flutuante; composição das unidades de análise; codificação e recortes; categorização e descrição das categorias. Após a leitura flutuante do corpus e a emersão das categorias empíricas, foram estas codificadas e validadas internamente por três pesquisadores-juízes que trabalham com esta técnica.

\section{Resultados e discussão}

As Representações Sociais sobre Adoção de Crianças por Casais Homoafetivos, elaboradas pelos universitários concluintes dos cursos de Psicologia e de Direito da UFPB, foram analisadas com base no material coletado nas entrevistas e ponderadas pela análise temática de conteúdo, que resultaram em três categorias empíricas e 12 subcategorias.

A Tabela 1 ilustra os dados relativos ao Posicionamento frente à Adoção de Crianças por Casais Homossexuais. Pode-se notar que os universitários de Direito e Psicologia majoritariamente demonstraram atitudes contrárias à adoção, com $51 \%$ para ambos os cursos. Quanto ao posicionamento Favorável à adoção, 29\% dos universitários de Direito e $40 \%$ dos de Psicologia se expressam positivamente, como se pode verificar nas falas dos atores sociais a seguir:

Não tenho nada contra. Desde que ocorra uma relação de respeito, de carinho e principalmente de responsabilidade. $O$ relacionamento entre duas pessoas mesmo sendo ambas do mesmo sexo só não deve ser avaliado sobre essas condições e sim sobre o contexto em que vivem, os estados psicológicos, o contexto de aceitabilidade enfim de profundo respeito e responsabilidade...

O mais importante é a capacidade de cuidar e assumir uma criança e não projetar papéis definidos... não acho que casais homossexuais sejam menos ou mais qualificados para criar uma criança... mas sim igual a qualquer outro casal... o que importa é a harmonia e o amor que existe neste casal... e existirá nesta família...

"Sou radicalmente contra, pois a adoção de casais do mesmo sexo, fere o princípio da lei natural... por isso minha posição é totalmente contrária a isso".

Tabela 1. Posicionamento frente à adoção de crianças por casais homossexuais.

\begin{tabular}{lcccc}
\hline \multirow{2}{*}{ Categoria e Subcategorias } & \multicolumn{2}{c}{ Psicologia } & \multicolumn{2}{c}{ Direito } \\
\cline { 2 - 5 } & $\boldsymbol{f}$ & $\%$ & $\boldsymbol{f}$ & $\%$ \\
\hline Contrário & 40 & 51 & 44 & 51 \\
Favorável & 31 & 40 & 25 & 29 \\
Dúvida & 07 & 09 & 17 & 20 \\
\hline Total & 78 & 100 & 86 & 100 \\
\hline
\end{tabular}


De forma semelhante aos achados da presente pesquisa, Figueirêdo (2003) pôde verificar entre os profissionais juristas, donas de casa, professores universitários e psicólogos que 50,2\% são contrários à adoção de crianças por pares homoafetivos por causa da orientação sexual dos candidatos.

Esse autor ainda destaca que o preconceito é algo inerente à adoção de crianças por casais homoafetivos, no entanto a divulgação na mídia e a atuação isolada de alguns magistrados têm contribuído para atenuar as atitudes conservadoras, de modo que, na atualidade, há uma preocupação maior com os aspectos relacionados à afetividade no processo de adoção.

O Instituto Brasileiro de Pesquisa Social (2006) realizou Pesquisa Nacional sobre Cidadania e Sexualidade, a qual participou uma amostra de 2.000 entrevistados em todo o território nacional. Pode-se observar que $93 \%$ dos entrevistados mencionaram que os direitos dos homossexuais devem ser respeitados. Por outro lado, de forma semelhante aos universitários paraibanos, a maioria dos participantes dessa pesquisa-51,82\% - mencionaram que são contrários à adoção de crianças por casais homoafetivos.

Em pesquisa realizada por Torres e Falcão (2005), observou-se que os universitários que acreditavam ser a homossexualidade relacionada à falta de caráter e valores morais do sujeito são contrários à adoção de crianças por esses casais. Essas autoras ainda mencionam que a etiologia da homossexualidade afeta diretamente as representações sociais dos participantes sobre a adoção por casais homoafetivos.

No que tange à adoção de crianças por pares homoafetivos, comumente percebem-se obstáculos na sociedade contemporânea, tendo a premissa de que o homossexual é uma pessoa perversa, incapaz de dar afeto para uma criança assim como de receber afeto desta. Tal fato provavelmente deve-se aos fatores sócio-históricos da construção e representação da homossexualidade ao longo dos tempos (Dias, 2001; Lacerda, 2001; Lacerda, Pereira, Camino, 2002; Machado, 2004).
De acordo com o observado na Tabela 2 em relação às Concepções/Descrições acerca da Adoção de Crianças por Casais Homossexuais, nota-se que a maioria dos universitários de Direito e Psicologia deram ênfase à necessidade de Aptidão Psicoafetiva para adoção, com $37 \%$ e $48 \%$ das respostas respectivamente. Destaca-se que sobretudo os universitários de Psicologia mencionaram que a adoção por homossexuais é algo Anormal, com $23 \%$ das unidades de análise. Um dado característico dos universitários de Direito diz respeito ao fato de os mesmos considerarem a adoção como Desnecessária (29\%) na sociedade contemporânea.

De forma consonante à ancoragem social dos universitários de ambos os cursos pesquisados acerca da Aptidão Psicoafetiva para adoção, o Estatuto da Criança e do Adolescente (1990) preconiza a necessidade de uma avaliação psicossocial favorável do adotante e de uma família que possa oferecer amor e um desenvolvimento saudável à criança.

No que tange às representações dos universitários de Psicologia que consideram a adoção dos pares homoafetivos como Anormal, estas são é corroboradas por Mello (2005) quando esse autor menciona que a homossexualidade é vista por muitos como misto de doença-pecado-crime, despertando rejeições de intensidades variadas em diferenciados segmentos da sociedade, o que faz com que os homossexuais sejam alvo de atitudes preconceituosas, intolerância e discriminação.

Entre os achados da pesquisa, uma subcategoria que merece destaque entre os grupos pesquisados, é a representação da Adoção de Crianças por Casais Homoafetivos como uma Atitude Inclusiva, considerada por $16 \%$ dos universitários do curso de Direito; e 10\% dos de Psicologia. Os dados a priori apresentados são instigantes uma vez que são contraditórios às concepções dos universitários acerca da adoção de crianças por casais homoafetivos. Tais dados possibilitam vislumbrar a viabilidade da adoção como forma de inclusão social, posto que a criança será inserida numa família que possivelmente lhe proporcionará amor, educação, cultura e cidadania.

Tabela 2. Descrições acerca da adoção de crianças por casais homossexuais.

\begin{tabular}{lcccc}
\hline \multirow{2}{*}{ Categoria e Subcategorias } & \multicolumn{2}{c}{ Psicologia } & \multicolumn{2}{c}{ Direito } \\
\cline { 2 - 5 } & $\boldsymbol{f}$ & $\%$ & 25 & $\%$ \\
\hline Anormal & 31 & 23 & 23 & 16 \\
Atitude Inclusiva & 13 & 10 & 52 & 37 \\
Aptidão Psicoafetiva & 64 & 48 & 40 & 29 \\
Desnecessária & 25 & 19 & 133 & 100 \\
\hline Total & 140 & 100 & & \\
\hline
\end{tabular}


Entre as unidades temáticas das falas dos universitários, foi possível destacar as representações sociais das Concepções/Descrições acerca da Adoção de Crianças por Casais Homossexuais:

"A criança que é criada entre homossexuais terá desvio de personalidade... vivendo numa anormalidade de comportamentos... e numa ausência da figura paterna e materna..."

"Sou a favor pois existem várias crianças que estão abandonadas... e muitas vezes poderiam ser supridas por uma adoção por casais homossexuais, como uma atitude de diminuir a exclusão social de crianças na ruas das grandes cidades..."

"A adoção como medida de diminuição de órfãos... carentes... e como complementação da vida a dois não me importando a opção sexual...”

"As crianças devem desde cedo ter nitidamente uma concepção e diferenciação entre as figuras materna e paterna. Além do que é possível que a criança sofra de preconceito... discriminação..."

"A configuração jurídica da estrutura família carece de uma adaptação aos novos tempos... aos novos perfis de família... Assim, casais homossexuais e famílias monoparentais tem se tornado muitos freqüentes para serem ignoradas pelo direito..."

Os dados da tabela 3 revelam as Conseqüências Biopsicossociais para as Crianças Adotadas por Casais Homossexuais: os universitários de ambos os cursos (Psicologia com $42 \%$ e Direito com $40 \%$ ) mencionaram que a criança pode sofrer Preconceito nas relações interpessoais da vida cotidiana. Ainda como conseqüência, pode-se verificar que os universitários de Direito (26\%) e Psicologia (32\%) apontaram Ausência de Referencial Paterno/Materno para a criança adotada numa família homoafetiva.

Os universitários pesquisados ancoraram também suas representações em consequiências relacionadas à Influência na Orientação Sexual da criança adotada por homossexuais. Tal fato é representado entre os futuros psicólogos com $15 \%$ das unidades de análise e entre os futuros juristas com $20 \%$.

Figueirêdo (2003) menciona que comumente as pessoas se posicionam contrárias à adoção por casais homoafetivos, tendo em vista que a inserção da criança nesta família poderá ocasionar 'risco' na orientação sexual e identitária da criança. De forma semelhante, os atores sociais, desta pesquisa, ancoraram suas Representações Sociais contrárias à adoção de crianças por casais homoafetivos embasados numa visão de que tal processo poderá acarretar consequiências psicossociais e morais à criança adotada.

De forma antagônica às representações dos universitários paraibanos, percebe-se na literatura científica que a inserção de crianças em famílias chefiadas por pares homoafetivos não provoca nenhum distúrbio nos seus aspectos psicossociais, afetivos e cognitivos quando comparados às crianças que possuem pais de orientação heterossexual (Bailey, Dobrow, Wolfe \& Mikack, 1995; Costa, 2006; Dias, 2004; Golombok \& Tasker, 1996).

Costa (2006) realizou pesquisa com homossexuais masculinos e femininos em Juiz de Fora - MG. Nesta pode-se observar que $93 \%$ destes atores sociais afirmaram que a adoção não influencia na orientação sexual das crianças. Ainda se pode verificar que 94\% dos homossexuais que já tinham experenciado a adoção não acreditam que tenham prejudicado as crianças.

De forma peculiar à formação profissional/acadêmica, pode-se verificar que os concluintes de Direito apontaram como conseqüências para a adoção as relacionadas ao surgimento de Problemas Morais (14\%); já os concluintes de Psicologia enfatizaram o surgimento dos Distúrbios Psicológicos (11\%) advindos da efetivação da adoção de crianças por casais homoafetivos.

Pode-se observar que as representações tanto dos universitários de Direito quanto de Psicologia foram ancoradas na formação acadêmica/profissional. Dias (2001, 2004), no entento, menciona que as evidências trazidas pelas

Tabela 3. Consequiências biopsicossociais para as crianças adotadas por casais homossexuais.

\begin{tabular}{lcccc}
\hline \multirow{2}{*}{ Categoria e Subcategorias } & \multicolumn{2}{c}{ Psicologia } & \multicolumn{2}{c}{ Direito } \\
\cline { 2 - 5 } & $\boldsymbol{f}$ & $\%$ & $\boldsymbol{f}$ & $\%$ \\
\hline Ausência de Referencial & 42 & 32 & 29 & 26 \\
Paterno/Materno & 56 & 42 & 44 & 40 \\
Preconceito & 20 & 15 & 22 & 20 \\
Influência na Orientação Sexual & 0 & 0 & 16 & 14 \\
Problemas Morais & 14 & 11 & 0 & 0 \\
Distúrbios Psicológicos & 132 & 100 & 133 & 100 \\
\hline Total & & & & \\
\hline
\end{tabular}


pesquisas científicas não permitem vislumbrar a possibilidade da ocorrência de distúrbios ou desvios de conduta nas crianças devido ao fato de possuírem dois pais ou duas mães.

Os Universitários representaram as Conseqüências Biopsicossociais para as Crianças Adotadas por Casais Homossexuais nas suas falas a seguir:

Não acho muito coerente, uma vez que é uma questão de difícil assimilação para a criança entender que seus pais são do mesmo sexo... e pelo método de comparação social esta criança pode desenvolver uma série de traumas... ou desequilíbrios... e sofrer preconceitos por parte das outras pessoas do seu grupo de pertença...

"Estando a criança na presença de homossexuais pode ser que ela fique tendenciada a este lado... que para mim não é doença... mas sim escolha errônea..."

"Faltará uma figura paterna ou materna com que esta criança possa se identificar para crescer e se desenvolver enquanto pessoa... a adoção poderia acarretar na criança problemas de desequilíbrio sobretudo de ordem moral."

É interessante ressaltar que as representações dos universitários de Direito e de Psicologia foram ancoradas em atitudes contrárias à adoção de crianças por casais homoafetivos, destacando consequiências psicossociais, orgânicas e morais nas crianças inseridas nesse modelo de família.

Pode-se verificar, ainda, que os universitários ancoraram suas representações em elementos concernentes as suas identificações acadêmica/profissionais, como, por exemplo, a elucidação de conseqüências da adoção pautadas no surgimento de distúrbios psicológicos e desvios de conduta. Por outro lado, observaram-se os posicionamentos dos universitários que atribuíram ao processo de adoção uma atitude inclusiva por parte dos casais homoafetivos, contribuindo para a diminuição significativa de crianças em situação de rua na realidade brasileira.

\section{Considerações Finais}

A presente pesquisa buscou investigar as representações sociais de universitários concluintes dos cursos de Direito e de Psicologia acerca da adoção de crianças por casais homoafetivos. Os resultados obtidos indicaram que não houve uma diferenciação significativa no que tange às representações dos universitários, de modo que ambos expressaram posicionamentos contrários à adoção no contexto da homossexualidade. Denota-se que tais posicionamentos devem-se, provavelmente, à ancoragem que os universitários expressaram em suas representações, demonstrando-a através das conseqüências como: "risco" de a criança seguir a mesma orientação sexual do adotante; da ausência do referencial materno/paterno, e de ser alvo de preconceito nas relações interpessoais.

Um dado que merece destaque é o fato de os universitários mencionarem, por outro lado, que a adoção de crianças por casais homoafetivos concerne a uma atitude inclusiva, tendo em vista que a prioridade no processo de adoção é o bem-estar geral da criança, o que independe da orientação sexual dos adotantes.

Pode-se observar, na presente investigação, o preconceito flagrante arragaido entre os jovens universitários frente à adoção de crianças por casais homoafetivos. Por outro lado, denota-se uma nova 'roupagem' com a sutilidade das atitudes preconceituosas. Infere-se que tal fato deve-se, provavelmente, à luta sociopolítica atribuída, sobretudo, aos movimentos dos homossexuais em favor dos direitos à diversidade sexual. Tal contexto deve servir de alerta para os responsáveis pelas formações acadêmicas desses futuros profissionais que poderão lidar diretamente com a adoção. Sugere-se uma reflexão sobre as possibilidades de mudanças no paradigma da sexualidade humana na contemporaneidade, principalmente no que se refere ao livre arbítrio de todos os cidadãos em relação a suas vidas amorosas, sexuais e familiares.

Evidenciou-se a necessidade do fomento de mecanismos psicossociais e jurídicos que contribuam na elucidação desta temática complexa e dinâmica na sociedade contemporânea. Neste cenário faz-se necessária a inserção, nas pautas, de investigações e intervenções acerca dos aspectos psicossociais, afetivos e jurídicos do processo de adoção no contexto da homossexualidade, para que profissionais de saúde e juristas atuem com o escopo de promover o bem-estar aos adotantes e aos adotados.

Denota-se a importância da realização de pesquisas de cunho psicossocial e jurídico a serem desenvolvidas, buscando compreender fatores motivacionais e socioafetivos do processo de adoção junto aos homossexuais masculinos e femininos, bem como investigar junto aos participantes de conselhos tutelares e a crianças que estejam no contexto de abrigos e orfanatos. Indaga-se: Será que, numa realidade em que haja maior visibilidade e aproximação do fenômeno estudado (adoção de crianças por pares homoafetivos), os resultados sejam diferentes? Como será pautado o compromisso social e ético destes futuros psicólogos e juristas na sua prática profissional frente a esta problemática biopsicossocial?

Sugere-se, de forma parcimoniosa, que os resultados desta pesquisa contribuam para a formulação de estratégias na implementação de políticas públicas para os homossexuais, de modo a fornecer subsídios na mudança dos estereótipos negativos e preconceitos relacionados aos pares homoafetivos, de modo que haja respeito e tolerância à diversidade na orientação sexual na sociedade brasileira. 


\section{Referências}

Alves, S. A., Oliveira, T. L., Baroni, V.,Franco, L. D., \& Zacarias, R. (2007). Adoção de crianças por homossexuais. Retirado em 27 jan. 2007, de http://www.viannajr.edu.br/jornal/dir/artigos/pdf/ Art03200601.pdf

Bailey, J. M., Dobrow, D., Wolfe, M., \& Mikack, S. (1995). Sexual orientation of adult son of gays father. Developmental Psychology, 35, 124-129.

Bardin, L. (2000) Análise de conteúdo. Lisboa, Portugal: Edições 70. (Original publicado em 1977)

Camino, L., \& Pereira, C. (2000). O papel de Psicologia na construção dos direitos humanos: Análise das teorias e práticas psicológicas na discriminação ao homossexualismo. Revista Perfil, 13(13), 49-69.

Costa, T. M. M. L. (2006). Adoção por pares homoafetivos: Uma abordagem jurídica e psicológica. Juiz de Fora, MG: Faculdade de Ciências Jurídicas e Sociais Vianna Júnior. Retirado em 08 nov. 2006, de http://www.viannajr.edu.br/revista/dir/doc/art_ 10005.pdf

Dias, M. B. (2001). União homossexual: O preconceito \& A justiça. Porto Alegre, RS: Livraria do Advogado.

Dias, M. B. (2004). Conversando sobre homoafetividade. Porto Alegre, RS: Livraria do Advogado.

Estatuto da Criança do Adolescente. (1990). Lei No 8.069, 13 de Julho de 1990. Retirado de http://www.planalto.gov.br/ccivil/ Leis/L8069.htm

Figueirêdo, L.C. B. (2003). Adoção para homossexuais. Curitiba, PR: Juruá.

Giddens, A. (1993). A transformação da intimidade: Sexualidade, amor e erotismo nas sociedades modernas. São Paulo, SP: Editora da Universidade Estadual Paulista.

Golombok, S., \& Tasker, F. (1996). Do parents influence the sexual orientation of their children? Findings from a longitudinal study of lesbian familiars. Developmental Psychology, 32, 3-11.

Instituto Brasileiro de Pesquisa Social. (2006). Pesquisa Nacional sobre Cidadania e Sexualidade. Rio de Janeiro, RJ: Autor

Ivo, M. L., Pelizaro, M. A. I., \& Zaleski, E. G. F. (2002, maio). Direitos do ser humano na opção sexual. Trabalho apresentado no VIII Simpósio Brasileiro de Comunicação em Enfermagem, Ribeirão Preto, SP.

Jodelet, D. (2001). As representações sociais. Rio de Janeiro, RJ: Editora da Universidade Estadual do Rio de Janeiro.

Jones, J. M. (1972). Prejudice and racism. Reading, MA: AffisonWesley.

Lacerda, M. T. (2001). A representação social da homossexualidade: O que pensam os estudantes universitários? Dissertação de Mestrado não-publicada, Universidade Federal da Paraíba, João Pessoa, PB.

Lacerda, M. T., Pereira, C., \& Camino, L. (2002). Um estudo sobre as formas de preconceito contra homossexuais na perspectiva das representações sociais. Psicologia: Reflexão e Crítica, 15(1), 165-178.

Lopes, M. A. S. (2006). União civil e a declaração da família nuclear: Uma análise do projeto de parceria civil registrada de pessoas do mesmo sexo. Revista Urutágua - Revista Acadêmica Multidisciplinar, 5, 1-21 Retirado em 08 nov. 2006, de http://www. urutagua.uem.br/005ru.htm

Machado, A. O. (2004). Identidade e discriminação: Um estudo realizado com homens e mulheres homossexuais. Dissertação de Mestrado não-publicada, Universidade Federal da Paraíba, João Pessoa, PB.
Mello,L. (2005). Outras famílias: A construção social da conjugalidade homossexual no Brasil. Cadernos Pagu, 24(1), 197-225.

Moscovici, S. (2003). Representações sociais: Investigações em Psicologia Social. Petrópolis, RJ: Vozes.

Torres, A. R. R., \& Falcão, L. C. (2005). Representações sociais sobre a união civil de pessoas do mesmo sexo. In Anais da IV Jornada Internacional e II Conferência Brasileira sobre Representações Sociais (pp. 1650-1654). João Pessoa, PB: Editora da Universidade Federal da Paraíba

Tylor, B. (1999). Coming out as a life transition: Homosexual identity formation and its implications for health care practice. Journal of Advanced Nursing, 30(20), 520-525

Vala, J. (2000). Representações sociais e Psicologia Social do conhecimento. In J. Vala \& M. B. Monteiro (Eds.), Psicologia Social (pp. 457-501). Lisboa, Portugal: Fundação Calouste Gulbenkian.

Weber, L. N. D. (2007). Quero que alguém me chame de filho ou do direito à convivência familiar e comunitária. Retirado em 30 jan. 2007, de http://lidiaw.sites.uol.com.br/convivenciafamiliar.htm

Ludgleydson Fernandes de Araújo é psicólogo, Mestre em Psicologia Social e Especialista em Gerontologia pela UFPB, Professor Assistente I do Departamento de Psicologia da Universidade Federal do Piauí (UFPI, Campus Ministro Reis Velloso Parnaíba/PI). Endereço para correspondência: Av. Padre Raimundo José Vieira, 2695 casa 02, Condomínio Comandante Parry, Bairro Fátima, CEP 64202-340 - Parnaíba/PI. ludgleydson@yahoo.com.br

Josevânia da Silva Cruz de Oliveira é psicóloga, mestranda em Psicologia Social pela UFPB e pesquisadora do Núcleo de Pesquisa Aspectos Psicossociais da Prevenção e da Saúde Coletiva da UFPB.

josevaniasco@gmail.com

Valdiléia Carvalho de Sousa é estudante de graduação em Psicologia e pesquisadora do Núcleo de Pesquisa: Aspectos Psicossociais da Prevenção e da Saúde Coletiva da UFPB.

valdileia@gmail.com

Alessandra Ramos Castanha é graduada em Psicologia pela Universidade Católica de Pernambuco (UNICAP), especialista em Psicologia Hospitalar pelo Centro de Psicologia Hospitalar e Domiciliar e mestre em Psicologia Social pela UFPB. Doutoranda da Faculdade de Filosofia, Ciências e Letras de Ribeirão Preto e Psicóloga voluntária do Hospital das Clínicas da Faculdade de Medicina de Ribeirão Preto da Universidade de São Paulo (USP).

\section{Adoção de crianças por casais homoafetivos: um estudo comparativo entre universitários de Direito e de Psicologia}

Ludgleydson Fernandes de Araújo, Josevânia da Silva Cruz de Oliveira, Alessandra Ramos Castanha e Valdiléia Carvalho de Sousa

Recebido: 10/11/2006

$1^{a}$ revisão: 02/02/2007

Aceite final: 07/05/2007 